\title{
ПРАВО СОБСТВЕННОСТИ НА ВОДНЫЕ ОБЪЕКТЫ: СРАВНИТЕЛЬНО-ПРАВОВОЕ ИССЛЕДОВАНИЕ
}

\section{OWNERSHIP RIGHT TO WATER BODIES: COMPARATIVE LEGAL RESEARCH}

\section{A. Krytsula}

Summary. This article examines the issues of ownership of water bodies, as well as the norms of civil and water legislation on this issue, their correlation. Attention is paid to the very concept of "water bodies" as a specific object of property turnover. The importance and civillegal significance of differentiating the concepts of "water" and "water body" is explained. The presumption of federal ownership of water bodies is investigated. Particular attention is paid to the analysis of the implementation of the ownership of the pond and the watered quarry, as water bodies that can be privately owned and are objects of property turnover. The problems of ownership of water bodies raised in scientific work are compared with similar legal structures of foreign legal orders.

Keywords: property right, water legal relations, water body, pond, watered quarry, water code, water use. This article is devoted to ownership on bodies of water according to Russian Civil Law and Russian Water Resources Law.
$\mathbf{\Pi}$ раво собственности на водные объекты в юридическом аспекте можно рассматривать с двух сторон: как правовой институт и как совокупность правомочий собственника.

Нормы, закрепленные в ВК РФ, регулируют специфические черты, характер права собственности на водные объекты и особенности механизма реализации правомочий собственника, а нормы, содержащиеся в ГК РФ, определяют общее содержание права собственности на водные объекты [5].

Некоторые исследователи считают, что в водном праве закреплен лишь механизм реализации права использовать воду (водные объекты) - права водопользования, в связи с чем в водном законодательстве преимущественно закрепляются отношения водопользования, а не собственности [4].

Однако также существует мнение, что правоприменителям следует принимать во внимание непосредственное намерение законодателя создать отдельный
Крыцула Алексей Алексеевич

К.ю.н., дочент, Северо-Кавказский филиал Российский государственный университет правосудия aakrytsula@gmail.com

Аннотация. В данной статье рассматриваются вопросы права собственности на водные объекты, а также нормы гражданского и водного законодательства по указанному вопросу, их соотношение. Уделяется внимание самому понятию «водные объекты», как специфическому объекту имущественного оборота. Объясняется важность и гражданско-правовое значение разграничения понятий «вода» и «водный объект». Исследуется презумпция федеральной собственности на водные объекты. Особое внимание занимает анализ осуществления права собственности на пруд и обводненный карьер, как водные объекты, которые могут находиться в частной собственности, и являются объектами имущественного оборота. Поднимаемые в научной работе проблемы права собственности на водные объекты сопоставляются с аналогичными правовыми конструкциями зарубежных правопорядков.

Ключевые слова: право собственности, водные правоотношения, водный объект, пруд, обводненный карьер, водный кодекс, водопользование.

правовой режим, а при наличии конкуренции между общей и специальной норм предпочтение должно быть отдано специальной норме [18].

Нормы ВК РФ не противоречат нормам гражданского законодательства, так как регулируется не только вопрос отчуждения земельного участка, но и судьба водных объектов, имеющих свой режим использования и защиты [11].

Еще в 2009 году в Концепции развития гражданского законодательства Российской Федерации [14] было указано, что в ГК РФ необходимо включить нормы, регламентирующие право собственности на такие объекты, как участки недр и водные объекты, и к данному праву следует в субсидиарном порядке применять нормы о праве собственности на земельные участки.

Такая позиция до сих пор поддерживается в научной литературе, отмечается необходимость переноса правил о праве собственности на водные объекты в ГК РФ, так как земельный участок и расположенный в его 
границах обособленный водный объект выступают в гражданских правоотношениях в качестве единого объекта гражданских прав [19].

В целях рассмотрения вопроса о праве собственности на водные объекты кратко рассмотрим понятие водного объекта, так как данные определения часто будут использоваться в настоящей статье и без их освещения восприятие норм законодательства о праве собственности на водные объекты может быть затруднено. Определение данных терминов также позволит понять последовательность действий законодателя или наоборот обнаружить пробелы в законе.

Понятие водного объекта закреплено в ст. 1 Водного кодекса Российской Федерации 2006 г. (далее - ВК РФ) и представляет собой природный или искусственный водоем, водоток либо иной объект, постоянное или временное сосредоточение вод в котором имеет характерные формы и признаки водного режима. Такое определение водного объекта в российском законодательстве позволяет понять, что водный объект - это не просто место, в котором присутствует вода, а представляет собой природный комплекс, единое неделимое природное образование земли и воды.

Некоторые исследователи также рассматривают в качестве объектов экологических отношений не водные объекты, а воды в их естественно природном состоянии [7]. Такой подход создает определенные препятствия при определении предмета прав субъектов водных отношений на указанные «воды», в связи правовую конструкцию водного объекта необходимо рассматривать в качестве соединения земли-недвижимости и водной массы [26].

В зависимости от особенностей режима, физико-географических, морфометрических и других особенностей ВК РФ разделяет водные объекты на две категории: поверхностные и подземные водные объекты.

В соответствии со ст. 5 ВК РФ поверхностный водный объект состоит из поверхностных вод и покрытых ими земель в пределах береговой линии, которая по-разному определяется законодателем для каждого вида водного объекта. При этом обязательным признаком поверхностных водных объектов является соединение земли и воды [13].

К подземным водным объектам водное законодательство относит бассейны подземных вод и водоносные горизонты. Несмотря на то, что в отношении подземных водных объектов ВК РФ отсылает к законодательству о недрах, в данном законодательстве используется такое понятие как «подземные воды», то есть вода рассматривается в качестве ресурса.
Пересмотр концепции исключительной государственной собственности на водные объекты, ранее существовавший в российском законодательстве, произошел в результате развития экономики и установления в Конституции РФ 1993 г. многообразия форм собственности на природные объекты.

Новый вид водных объектов - обособленные водные объекты - впервые был определен в ВК РФ 1995 г., данные водные объекты могли находиться в различных формах собственности, в т.ч. частной.

В ныне действующем ВК РФ закреплена презумпция государственной собственности на поверхностные водные объекты, исключение из которые составляют обособленные водные объекты (пруды и обводненные карьеры) - они могут находиться в собственности субъекта, муниципального образования, физического или юридического лица, если данные объекты расположены на земельном участке, принадлежащем соответствующему лицу на праве собственности. Таким образом, в водном законодательстве закреплено 3 вида права собственности: государственная, муниципальная и частная.

В отношении подземных водных объектов указанные выше исключения не предусмотрены, согласно ст. 1.2 Закона РФ от 21.02.1992 № 2395-1 «О недрах» недра в границах территории Российской Федерации, включая подземное пространство и содержащиеся в недрах полезные ископаемые, энергетические и иные ресурсы, являются государственной собственностью. Участки недр не могут быть предметом купли, продажи, дарения, наследования, вклада, залога или отчуждаться в иной форме.

Таким образом, закреплена исключительная государственная собственность на подземные водные объекты. Такой подход позволяет государству как контролировать объемы извлекаемых водных ресурсов, так и получать выгоду посредством предоставления на возмездной основе права пользования водными объектами иным лицам.

Указанная выше презумпция также закреплена в пункте 2 статьи 214 ГК РФ, согласно которому земля и другие природные ресурсы, не находящиеся в собственности граждан, юридических лиц либо муниципальных образований, являются государственной собственностью.

Установление презумпции государственной собственности на водные объекты также прямо корреспондирует статье 9 Конституции РФ 1993 г., согласно которой природные ресурсы являются основой жизни 
и деятельности народов, проживающих на соответствующей территории.

Возможность приобретения некоторых водных объектов в частную собственность (прудов и обводненных карьеров) и наличие равного доступа к приобретению права пользования являются одними из принципов, обеспечивающих социальную справедливость в области водных правоотношений [27].

Существует мнение, что такое сложившееся отношение законодателя к водным объектам вполне оправданно, так как передача водных объектов в частную собственность привело бы к реальной угрозе экономической безопасности государства, а также при наличии многообразия форм собственности на природные ресурсы были бы созданы риски сосредоточения большинства природных богатств в руках узкого круга людей [2]. Также иные исследователи отмечают, что В Конституции РФ 1993 г. отражена идея социальной функции собственности, что вытекает из принципа социального государства, а также из системного толкования ст. 9 Конституции РФ 1993 г. [30]. Разрешение вопроса о преимуществе федеральной собственности на новые объекты также логично вытекает из того, что Российская Федерация является федеральным государством [6].

Однако также существует мнение, что непосредственные интересы человека (экологические, социальные, культурно-просветительские, оздоровительные) преобладают над коммерческим (экономическим) интересом государства, в связи с чем государство должно ограничивать свои полномочия в пользу общественного интереса в использовании данных объектов [12].

Принадлежащие государству, субъектам или муниципальным образованиям водные объекты, а также их береговые полосы (протяженность установлена отдельно для каждого вида водного объекта) считаются общедоступными, в связи с чем любой человек вправе использовать общедоступные водные объекты для личных или бытовых нужд (при соблюдении правил и ограничений, установленных законом).

В связи с существованием нескольких форм собственности на поверхностные водные объекты, законодательством предусмотрена возможность совершения различных гражданско-правовых сделок (например, купля-продажи, аренда) в отношении прудов и обводненных карьеров вместе с прилегающими земельными участками.

В свою очередь, ВК РФ не содержит определение «понятий пруд» и «обводненный карьер», которые по- мимо государственной могут находиться в муниципальной и частной собственности.

В толковом словаре С.И. Ожегова указано, что пруд - это водоем в естественном или выкопанном углублении, а также запруженное место в реке[19].

Верховный Суд РФ указал, что из системного толкования приведенных положений ст. 1, 5, 8 ВК РФ в негосударственной собственности могут находиться только пруды (состоящие из поверхностных вод и покрытых ими земель в пределах береговой линии), обладающче признаками изолированности и обособленности от других поверхностных водных объектов, то есть не имеющче гидравлической связи с иньми водными объектами. Если пруд не обособлен и не изолирован от других поверхностных водных объектов и имеет с ними гидравлическую связь, он относится к собственности Российской Федерации, в том числе и в случае, когда пруд образован на водотоке (реке, ручье, канале) с помощью водонапорного сооружения[20].

Минприроды России в 2012 году разъяснило, что права собственности на водные объекты (имеются ввиду водные объекты, находящиеся в государственной собственности) и права собственности на создаваемые на водотоках подпорные гидротехнические сооружения не связаны между собой - последние могут находиться в различных формах собственности (государственной, муниципальной, частной). При этом созданный на водотоке новый объект будет иметь все правовые основания для установления на него федеральной формы собственности. В таком случае собственник гидротехнического сооружения имеет права владения, пользования и распоряжения гидротехническим сооружением как объектом недвижимости [21].

Сведения о гидротехнических и иных сооружениях, расположенных на водных объектах, о кадастровых номерах земельных участков, в границах которых расположены водные объекты, и земельных участков, занятых указанными сооружениями, а также о документах, на основании которых зарегистрировано право собственности, подлежат внесению в государственный водный реестр в соответствии с пунктом 12 Положения о ведении государственного водного реестра [23].

Министерство экономического развития указало, что если для самостоятельного создания пруда требуется только проведение земляных работ, то разрешение на строительство не требуется, однако если требуется строительство гидротехнического сооружения, то требуется получение разрешения на строительство указанного сооружения, а не самого водного объекта [22]. 
В связи с отсутствием понятия «пруд» в водном законодательстве Российской Федерации возможно применение терминов и понятий, содержащихся в ГОСТах в части, не противоречащей нормам законодательных актов Российской Федерации [9]. Согласно ГОСТу 19179-73 «Гидрология суши. Термины и определения» [10] пруд - это мелководное водохранилище площадью не более 1 км., а пруд-копань - небольшой искусственный водоем в специально выкопанном углублении на поверхности земли, предназначенный для накопления и хранения воды для различных хозяйственных целей.

По мнению исследователей, отсутствие в законе указания на необходимость исключения гидравлической связи прудов с иными водными объектами создает проблемы в правоприменительной практике, и для преодоления данного пробела юридическое понятие «пруд» необходимо закрепить в ВК РФ, позаимствовав определение из ГОСТа [31]. На настоящий момент наличие определения разных видов водных объектов в ГОСТах не имеют обязательной силы и не восполняют пробел законодательства [28].

Также существует мнение, что в реальной жизни отсутствие гидравлической связи с другими поверхностными водными объектами встречается очень редко, так как может существовать незаметная человеку косвенная гидравлическая связь с поверхностными водами через подземные горизонты и родники [6].

В 2017 году на сайте Министерства природных ресурсов и экологии РФ был опубликован ответ на запрос, связанный с юридическим обоснованием понятия термина «пруд».

Министерство природных ресурсов и экологии РФ указало, что «для пруда характерен слабый уклон дна, достаточно крутые берега, устойчивое к размыву ложе. Они сооружаются на реках, ручьях, оврагах, логах, балках, карьерах. Глубина, как правило, составляет около 3-5 метров, а площадь акватории достигает 1 кв. км. Если размеры и глубины превышают указанные параметры, речь идет о водохранилищах».

Министерство природных ресурсов и экологии РФ также указало, что в правовых отношениях обособленные водные объекты выступают как принадлежность земельного участка, в границах которого они расположены [9].

Обводненные карьеры имеют схожие характеристики с прудами, и во многом близки к ним. Карьеры представляют собой выемки в земной коре, которые образуются при добыче полезных ископаемых. Как пра- вило, обводненный карьер не используется для добычи полезных ископаемых, а его заполнение происходит естественным или искусственным образом [15].

Однако отсутствие закрепленных в законодательстве критериев определения разновидности водного объекта (применительно к пруду или обводненному карьеру) может создать ситуацию, когда разновидность водного объекта будет определяться субъективно, что позволит отчуждать водный объект в нарушение интересов общества и приведет к причинению имущественного вреда государству [5].

Возникновение и прекращение права собственности на водный объект неразрывно связывается с возникновением или прекращением права собственности на земельный участок, на котором размещен водный объект. Именно в связи с неразрывностью земельного участка и водного объекта второй следует юридической судьбе первого.

Таким образом, не допускается отдельное отчуждения водного объекта и земельного участка, а также не разрешается раздел земельного участка, если в результате его разделения будет произведен раздел водного объекта (пруда, обводненного карьера).

Согласно п. 2 ст. 261 ГК РФ право собственности на земельный участок распространяется на находящиеся в границах этого участка поверхностный (почвенный) слой и водные объекты, находящиеся на нем растения. Из этого следует, что гражданским законодательством водный объект признается частью земельного участка, на который автоматически распространяется право собственности.

Некоторые исследователи называют обособленные водные объекты в правовых отношениях как принадлежность земельного участка, сравнивания с определением главной вещи и принадлежности, установленным в 135 ГК РФ [5].

Также существует мнение, что из толкования статей 130 и 261 ГК РФ следует, что обособленный водный объект может выступать самостоятельным объектом гражданско-правового оборота, и может быть объектом купли-продажи, залога и иных сделок, предусмотренных гражданским законодательством».

Однако данную позицию можно легко подвергнуть критике, так как в случае передачи водного объекта в залог обращение на него взыскания невозможно (например, с трудом представляется возможность перевозки дна пруда и воды в иное место, определенное залогодержателем). 
Некоторые исследователи вообще указывают, что водные объекты по своей правовой природе не являются недвижимым имуществом, так как в соответствии со ст. 3 ВК РФ они признаны природным объектом и природным ресурсом [1].

При рассмотрении водного объекта как объекта гражданских прав (пруда или обводненного карьера, находящегося в частной собственности), можно сделать вывод, что водный объект относится к недвижимому имуществу на основании ст. 130 ГК РФ, так как он неразрывно связан с земельным участком.

В пункте 3 ст. 209 ГК РФ закреплено, что владение, пользование и распоряжение землей и другими природными ресурсами осуществляются их собственником свободно, если это не наносит ущерба окружающей среде и не нарушает прав и законных интересов других лиц.

Также в ст. 129 ГК РФ закреплено, что земля и другие природные ресурсы могут отчуждаться и переходить от одного лица к другому иным способом в той мере, в какой их оборот допускается законами о земле и другими природными ресурсами.

В соответствии с п. 3 ст. 261 ГК РФ собственник земельного участка вправе использовать по своему усмотрению все, что находится над и под поверхностью этого участка, если иное не предусмотрено законами о недрах, об использовании воздушного пространства, иными законами и не нарушает прав других лиц.

При толковании статей 129, 209, 261 ГК РФ можно прийти к выводу о том, что применение к природным ресурсам, в том числе к воде, института права собственности имеет свои принципиальные особенности. Например, в гражданском законодательстве прослеживается наличие «экологических приоритетов», так как собственник вправе осуществлять свои права лишь в той мере, пока это не наносит ущерба окружающей среде и не нарушает прав и законных интересов других лиц.

Так как сосредоточенная в водных объектах вода имеет текучее состояние, что позволяется ей находиться в состоянии непрерывного движения и водообмена, то к ним не может быть в полной мере применено правомочие владения, однако у собственника имеется возможность затруднять или исключать третьим лицам доступ к водным объектам, что, в свою очередь, охватывается понятием владения [23].

Собственник водного объекта имеет право предоставить третьему лицу пользование водным объектом (выбор способа предоставления права пользования зависит от целей предполагаемого водопользования, которые закреплены в ст. 11 ВК РФ).

В части 5 ст. 8 ВК РФ также указано, что естественное изменение русла реки не влечет за собой прекращение права собственности РФ на этот водный объект. Данное правило не вызывает особых дискуссий в пределах РФ [8], однако неразрешенным остается вопрос с водными объектами, которые могут выйти за пределы РФ. Очевидно, в таких случаях будут действовать двусторонние соглашения, однако в ВК РФ данный вопрос остается неразрешенным.

Таким образом, при рассмотрении прав собственника на водные объекты можно выделить следующие особенности:

- собственником не может быть осуществлено непосредственное владение водой, так как она находится в непрерывном движении (во всех своих проявлениях);

- ограничивается право собственника на свободное отчуждение водного объекта (за исключением прудов и обводненных карьеров) в связи с отношением к водным объектам как к природным ресурсам;

- зачастую возникают трудности при определении разновидности и границ водного объекта, которое находится в собственности, в связи с невозможностью точного определения наличия/отсутствия гидравлической связи водных объектов под землей;

- водные объекты требуют постоянного мониторинга в связи с их изменчивым характером.

При рассмотрении опыта зарубежных стран хочется отметить, что технический прогресс XX века заставил наращивать различные государства массив водного законодательства, в результате чего приоритетными задачами были определены охрана водотоков, водоемов, акваторий морей [3].

Исследователи отмечают, что в мировом сообществе преобладает принцип государственной собственности на воду, который распространяется на поверхностные воды, атмосферные осадки и подземные воды. В Боннской декларации закреплено, что именно правительства несут основную ответственность за обеспечение эффективного и справедливого выделения ресурсов и управления ими[24].

При этом новой тенденцией в рамках управления водными ресурсами стало внедрение системы продаваемых прав собственности на водные ресурсы. Данная тенденция зародилась в западных штатах США, что 
позволяет продаваемые права первому водопользователю «продавать лишнее количество воды на рынке, т.е. торговать правом собственности на воду» [16].

Положения Модельного водного кодекса для государств - участников СНГ [17] в целом содержат аналогичные положения, как и в российском законодательстве в отношении права собственности на водные объекты, а также правомочий и ограничений прав собственников в отношении водных объектов.

Государства Западной Европы и Северной Америки признают право собственности на водные объекты за государством или муниципальными образованиями, а возможность нахождения в частной собственности предоставляется только в отношении небольших по площади и нередко рукотворных водных объектов. Крупные водные объекты воспринимаются как «общее достояние» [25].

В Китае отсутствуют частные водные объекты, вода представляет собой общественное благо, государство управляет и контролирует использование, поставку и распределение водных запасов, что является одной из составляющих плановой экономики Китая. В Швейцарии эффективную позитивную роль сыграл Союз охраны природы, который приобрел в собственность ряд озер, что позволило активистам Союза контролировать водоемы, находящиеся в частной собственности. В некоторых штатах США также часть прав предоставлены негосударственным организациям, которые вправе контролировать правильность распределения вод. В Испании предусматривается общественная собственность на морскую береговую зону, однако природные ресурсы находятся в государственной собственности.

В Болгарии и Словении закреплена государственная собственность на поверхностные водные объекты вместе с сопряженными к ним дном и берегом.

В Чешской Республике поверхностные или подземные водные объекты не являются предметом (частного) права собственности, а в Эстонии водоемы могут находиться в частной собственности, если они расположены в границах участка, находящегося в частной собственности данного лица [16].

Несмотря на то, что всеми государствами признается важная роль «воды» (и в том числе водных объектов) в жизни народов соответствующих территорий, каждая правовая система содержит собственные нормы регулирования водных отношений, учитывающих особенности соответствующих государств.

\section{ЛИТЕРАТУРА}

1. Абанина Е.Н., Аверьянова Н.Н., Анисимов А.П. и др. Актуальные проблемы теории земельного права России: монография / под ред. А.П. Анисимова. М.: Юстицинформ, - 2020.800 с.

2. Аверьянова Н.Н. Конституционно-правовое регулирование земельных отношений в Российской Федерации: монография / под ред. Г.Н. Комковой. М.: Юстицинформ, - 2017. - 264 с.

3. Боголюбов С. А. и др. Институты экологического нрава. М.: Эксмо, - 2010, С. 345-364.

4. Боголюбов С.А. Постатейный комментарий к Водному кодексу Российской Федерации / М.: Юстицинформ, - 1996. // СПС Консультант Плюс.

5. Боголюбов С.А., Кичигин Н.В., Пономарев М.В. Комментарий к Водному кодексу Российской Федерации (постатейный). М.: Юстицинформ,- 2007.312 c.

6. Боголюбов С.А., Сиваков Д.О. Комментарий к Водному кодексу Российской Федерации от 3 июня 2006 г. N74-Ф3 (постатейный) // Законодательство и экономика. - 2007. — № 5. С. 3-137.

7. Бринчук М.М. Экологическое право: объекты экологических отношений. М., 2011. С. 76-83.

8. Вопрос о принадлежности права собственности на территории нескольких субъектов, муниципальных образованиях, поселениях разрешен в ст. 7 Федерального закона от 03.06.2006 № 73-Ф3 «0 введении в действие Водного кодекса Российской Федерации».

9. Вопрос-ответ // Минприроды России: официальный сайт. 2017. URL: http://oldsite.zapoved.ru/activities/answer.php? PAGEN_1=9 (дата 0бращения: 31.05.2021).

10. ГОСТ 19179-73. Государственный стандарт Союза ССР. Гидрология суши. Термины и определения / введен в действие Постановлением Госстандарта СССР от 29 октября 1973 г. 2394 // СПС Консультант Плюс.

11. Комментарий к Водному кодексу Российской Федерации (постатейный) / под ред. А.А. Ялбулганова. — 2010 // СПС Консультант Плюс.

12. Комментарий к Водному кодексу Российской Федерации от 3 июня 2006 г. N74-Ф3 (постатейный) / Под ред. 0.Л. Дубовик // СПС КонсультантПлюс.2011.

13. Концепции развития российского законодательства / под ред. Т.Я. Хабриевой, Ю.А. Тихомирова. — М.: Эксмо, — 2010. С. $350-353$.

14. Концепция развития гражданского законодательства Российской Федерации (одобрена решением Совета при Президенте Российской Федерации по кодификации и совершенствованию гражданского законодательства от 07.10.2009) // Вестник ВАС РФ. — 2009.— № 11, ноябрь.

15. Лемкина Е.Н. Право собственности на водные объекты / Сибирский юридический вестник.— 2010.— № 3(50). С. 60. 
16. Лю Цин. Исследование развития прав собственности на водные ресурсы и их применения в Китайской Народной Республике и других странах / Международные аспекты водного законодательства / под ред. Г.А. Карлова. — М.; Издание Государственной Думы, — 2015. С. 53-58.

17. Межпарламентская ассамблея государств - участников Содружества Независимых Государств 16 ноября 2006 г. // Информационный бюллетень государств - участников СНГ. Приложение. 2007. N39.

18. Научно-практический комментарий к Водному кодексу Российской Федерации от 03.06.2006 N74-Ф3 (постатейный) / под ред. Ю.В. Сорокиной.2017 // СПС Консультант Плюс. 2017.

19. Ожегов С.И., Шведова Н.Ю. Толковый словарь русского языка, 1949-1992. М.: Азъ, - 1992.

20. Определение Судебной коллегии по экономическим спорам Верховного Суда РФ № 301-ЭС18-10194 от 06.12.2018 по делу № А39-7480/2015; 06зор судебной практики Верховного Суда Российской Федерации № 2 (2019), утв. Президиумом Верховного Суда РФ от 17.07.2019 // СПС Консультант Плюс.

21. Письмо Минприроды России от 23.08.2012 N03-14-33/13260 «0 праве собственности на водных объектах» // СПС Консультант Плюс.

22. Письмо Минэкономразвития РФ от 17.08.2011 № 0Г-Д23-962 // СПС Консультант Плюс.

23. Положение о ведении государственного водного реестра утверждено Постановлением Правительства РФ от 28 апреля 2007 г. № 253 «0 порядке ведения государственного водного реестра» // СПС Консультант Плюс.

24. Салман М.А. Салман, Даниел Д. Брадлоу. Нормативно-правовые основы управления водными ресурсами: базовые элементы и новые тенденции // Юридический сборник «Международное и национальное водное право и политика». - 2006. — № 1(15). С. 89-104.

25. Сиваков Д.О. Водное право России и зарубежных государств. М.: Юстицинформ, - 2010. С. 305-308.

26. Сиваков Д.О. Водный объект и водный фонд как правовые понятия // Lex russica. — 2016. — № 6. C. 91-102.

27. Сиваков Д.0. Коррупционные проявления в области водных отношений и меры по их снижению // Журнал российского права.— $2018 .-$ № 10. С. 156-164.

28. Судебная практика в современной правовой системе России: монография / под ред. Т.Я. Хабриевой, В.В. Лазарева. М.: ИЗиСП, НОРМА, ИНФРА-М,2017. 432 c.

29. Суханов Е.А. Вещное право: научно-познавательный очерк. М.: Статут, — 2017. 560 с.

30. Эбзеев Б.С. Человек, народ, государство в конституционном строе Российской Федерации. — М.: Юрид. литература, 2005. С. 67.

31. Ястребов А.Е. Право собственности на пруды: спорные вопросы законодательства и судебной практики // Экологическое право.— 2017. № — 1.— C. 30-32.

( ) Крыцула Алексей Алексеевич ( aakrytsula@gmail.com ).

Журнал «Современная наука: актуальные проблемы теории и практики» 